\title{
The effect of laughter therapy on radiation dermatitis in patients with breast cancer: a single-blind prospective pilot study
}

This article was published in the following Dove Press journal:

OncoTargets and Therapy

4 November 2014

Number of times this article has been viewed

Moonkyoo Kong'

Sung Hee Shin ${ }^{2}$

Eunmi Lee ${ }^{3}$

Eun Kyoung Yun ${ }^{2}$

'Department of Radiation Oncology, Kyung Hee University Medical Center, Kyung Hee University School of Medicine, ${ }^{2}$ College of Nursing Science, Kyung Hee University, ${ }^{3}$ Department of Quality Improvement, Kyung Hee University Medical Center, Seoul,

Republic of Korea
Correspondence: Eun Kyoung Yun College of Nursing Science, Kyung Hee University, 26 Kyungheedae-ro, Dongdaemun-gu, Seoul, |30-70| Republic of Korea

Tel $+82296 \mid 2348$

Fax +8229619398

Email ekyun@khu.ac.kr
Background: There have not yet been any published studies on the effects of laughter therapy on radiation-induced dermatitis in breast cancer patients treated with radiotherapy (RT). We assessed the effectiveness of laughter therapy in preventing radiation dermatitis in patients with breast cancer.

Methods: Thirty-seven patients were prospectively enrolled in this study. Eighteen patients were assigned to the experimental group and the other 19 patients were assigned to the control group. The patients who were assigned to the experimental group received laughter therapy during RT. Laughter therapy was started at the onset of RT and was provided twice a week until completion of RT. The patients who were assigned to the control group only received RT without laughter therapy. The grade of radiation dermatitis was scored by a radiation oncologist who was blinded to subject assignment. The patients' evaluation of pain within the RT field was also assessed.

Results: In the experimental group, radiation dermatitis of grade 3, 2, and 1 developed in five (33.3\%), five (33.3\%), and five patients (33.3\%), respectively. In comparison, in the control group, radiation dermatitis of grade $3,2,1$, and 0 developed in seven $(36.8 \%)$, nine $(47.4 \%)$, two $(10.5 \%)$, and one patient $(5.3 \%)$, respectively. The experimental group exhibited a lower incidence of grade 2 or worse radiation dermatitis than the control group (33.3\% versus $47.4 \%)$. The mean maximal pain scores in the experimental and control group were 2.53 and 3.95 , respectively. The experimental group complained of less severe pain than the control group during RT. However, these differences were not statistically significant.

Conclusion: The results of this study show that laughter therapy can have a beneficial role in preventing radiation dermatitis in patients with breast cancer. To confirm the results of our study, well-designed randomized studies with large sample sizes are required.

Keywords: breast cancer, radiotherapy, radiation dermatitis, laughter therapy

\section{Introduction}

Radiation dermatitis is the most common acute adverse effect of radiotherapy (RT) in patients with breast cancer. ${ }^{1,2}$ Several clinical studies have been conducted to evaluate the efficacy of various topical agents in preventing or minimizing radiation dermatitis in patients treated with RT; however, the results of these studies have been contradictory or unclear. ${ }^{3-9}$ Therefore, to date, there has been no consensus on the gold-standard approach for prevention or minimization of radiation dermatitis in patients with breast cancer.

In 1976, Norman Cousins reported that 10 minutes of laughter as a result of viewing comic films had a considerable analgesic effect in patients with ankylosing spondylitis. ${ }^{10}$ Since then, many researchers have investigated the therapeutic efficacy 
of laughter, and reported that laughter can have positive and quantifiable effects on certain aspects of health, such as oncology, ${ }^{11-13}$ psychiatry, ${ }^{14-16}$ rehabilitation, ${ }^{17}$ immunology, ${ }^{18}$ pulmonology, ${ }^{19}$ and palliative care. ${ }^{20}$ Although randomized controlled clinical trials with large sample sizes have not been conducted to validate the therapeutic efficacy of laughter, laughter has been used therapeutically for a variety of medical conditions. ${ }^{21,22}$ Also, in Japan, Hajime Kimata reported that laughter therapy has a beneficial role in the treatment of patients with skin problem such as allergic dermatitis. ${ }^{23-25}$ However, there have not yet been any published studies on the effects of laughter therapy on radiation-induced dermatitis. In this study, we assessed the effectiveness of laughter therapy in preventing or minimizing radiation dermatitis in patients with breast cancer.

\section{Materials and methods}

Patient eligibility criteria included the presence of pathologically confirmed unilateral breast cancer, no tumor invasion of the skin, completion of breast conserving surgery with or without adjuvant chemotherapy, receipt of postoperative RT to the breast, receipt of total RT dose $\geq 45$ Gy, no use of bolus, no concurrent chemotherapy, no history of prior RT to the chest wall, no history of connective tissue disorder, and no rashes or unhealed wounds in the RT field.

From July 2013 to January 2014, 37 patients were prospectively enrolled in this study. Eighteen patients were assigned to the experimental group and the other 19 patients made up the control group. The assignment of patients was based on the patient's preferences. The patients who wanted to receive laughter therapy were assigned to the experimental group, and the others were assigned to the control group. The patients who were assigned to the experimental group received laughter therapy during RT. Laughter therapy consisted of the delivery of information about laughter and active motion which was designed to produce laughter, especially mirthful laughter and self-induced stimulated laughter, and each session lasted 60 minutes. The laughter intervention consisted of three parts: introduction, enhancement, and wrap up. The detailed contents of laughter therapy are summarized in Table 1. Laughter therapy was started at the onset of RT and provided twice a week until completion of RT. To confirm that patients really laughed during laughter therapy, laughter was assessed through staff observations. Also, the feelings of patients were assessed by questionnaires before and after laughter therapy. The patients who did not mirthfully laugh more than 10 times in each laughter therapy session were excluded from this study. The patients who did not enjoy
Table I Laughter therapy contents

\begin{tabular}{lll}
\hline Step & Content & $\begin{array}{c}\text { Duration } \\
\text { (minutes) }\end{array}$ \\
\hline Introduction & $\begin{array}{l}\text { Self-introduction, simple breathing, } \\
\text { friendly greeting, facial } \\
\text { muscle stretching, health clap }\end{array}$ & 10 \\
Enhancement & $\begin{array}{l}\text { Delivery of information } \\
\text { What is laughter therapy? }\end{array}$ & 40 \\
& Effect of laughter \\
& Effect of praise \\
Influence of positive thinking & \\
& The importance of finding your \\
& self-confidence \\
& Learn to accept yourself as you are \\
& Opening one's heart to forgiveness \\
and thankfulness & \\
Active motion \\
Laughing in the mirror \\
Laughing dance with music \\
Laughter exercise with rhythmic \\
clapping \\
Movement while maintaining eye \\
contact with others \\
Quiet and deep breathing, relaxation, \\
embrace and say goodbye, giving one's \\
thoughts
\end{tabular}

the laughter therapy, as assessed by questionnaire, were also excluded. Patients who were assigned to the control group received RT without laughter therapy. Any prophylactic creams or lotions for radiation dermatitis were not allowed in either group. The institutional review board of the Kyung Hee University Medical Center approved this study, and all research was carried out in compliance with the Helsinki Declaration. We obtained informed consent from all patients prior to the study.

RT was delivered using a photon beam to the whole breast. With a schedule of 2 Gy per fraction and five fractions weekly, the whole breast was treated with tangential fields to 46-50 Gy. In patients with risk factors for local recurrence (lymphovascular invasion, close margin, or positive axillary lymph nodes), an electron boost to the tumor bed with an additional dose of 10-16 Gy was implemented. Infraclavicular or supraclavicular lymph nodal irradiation was also delivered to patients with risk factors for regional recurrence (lymphovascular invasion, positive axillary lymph nodes, or extranodal extension), with a total dose of 50-60 Gy. Bolus was not used in any of the patients.

All patient records included estrogen receptor (ER), progesterone receptor (PR), and human epidermal growth factor receptor-2 (HER2) status. Patients were classified according to receptor status: luminal (ER-positive or PR-positive), 
triple negative (ER-negative, PR-negative, HER2-negative), and HER2-positive (ER-negative, PR-negative, and HER2-positive). ER and PR status was determined by immunohistochemistry staining. Positive HER2 status was determined using either immunohistochemistry $3+$ staining or amplification on fluorescence in situ hybridization.

Patients were examined at baseline, and at weekly intervals from the start of RT until 8 weeks after its completion. The grade of radiation dermatitis was scored according to the Radiation Therapy Oncology Group criteria by a radiation oncologist who was blinded to subject assignment. The patients' evaluation of pain within the RT field was assessed with a $10-\mathrm{cm}$ visual analog scale. At the initiation of RT and 1 week after RT completion, serum levels of epidermal growth factor (EGF), transforming growth factor (TGF)- $\beta$, and fibroblast growth factor (FGF) were checked from all patients.

The primary endpoint was the maximum grade of radiation dermatitis developed during $\mathrm{RT}$ and the follow-up period. The secondary endpoint was the maximum pain score and serum growth factors level. Baseline characteristics of the two groups of patients were compared using the independent $t$-test or chi-square test. To assess differences in the maximum grade of radiation dermatitis between the two groups, we compared the actuarial rate of radiation dermatitis estimated using the Kaplan-Meier method, and comparison among groups was performed using the log-rank test. Elapsed time was calculated from the date of initiation of RT to the date of occurrence of maximum radiation dermatitis or final follow-up visit. The maximum pain score and serum growth factors level between the two groups was compared using the independent $t$-test. Parameters evaluated as potential predictive factors for radiation dermatitis were age, total RT dose, lymph nodal irradiation, body mass index, adjuvant chemotherapy, breast size, cancer molecular subtypes, and laughter therapy. All parameters were categorized into two groups according to distribution. The correlation of the development of radiation dermatitis with potential predictive factors was determined using the log-rank test. The Cox proportional hazard regression model was used for multivariate analysis. All tests were two-sided and $P<0.05$ was considered statistically significant. All analyses were performed using SPSS version 18.0 (IBM Corporation, Armonk, NY, USA).

\section{Results}

All patients completed scheduled RT without treatment interruption. Three patients in the experimental group did not receive laughter therapy more than three times, and these patients were excluded from the study. The remaining 15 patients in the experimental group received laughter therapy as planned. Therefore, 15 patients in the experimental group and 19 patients in the control group were evaluated and followed-up until 8 weeks after completion of RT. The staff confirmed that all patients in the experimental group mirthfully laughed more than ten times during laughter therapy. Also, all patients were satisfied and enjoyed laughter therapy, as assessed by questionnaire. No patients experienced side effects from laughter therapy.

Patient characteristics are summarized in Table 2. The patients in the experimental group were older than those in the control group, and more patients in the experimental group had underlying diabetes mellitus than in the control group. In addition, the patients in the experimental group had larger breasts than those in the control group. However, there were no significant differences in other characteristics between the two groups.

In the whole evaluable patient population, grade 3 radiation dermatitis developed in 12 patients (35.3\%), grade 2 in 14 patients $(41.2 \%)$, and grade 1 in seven patients $(18.9 \%)$. One patient did not experience radiation dermatitis. In the experimental group, radiation dermatitis of grades 3,2 , and 1 developed in five $(33.3 \%)$, five $(33.3 \%)$, and five $(33.3 \%)$ patients, respectively. In comparison, in the control group, radiation dermatitis of grades $3,2,1$, and 0 developed in seven $(36.8 \%)$, nine $(47.4 \%)$, two $(10.5 \%)$, and one $(5.3 \%)$ patient, respectively (Table 3 ). The experimental group had a lower incidence of grade 2 or worse radiation dermatitis than the control group (66.7\% versus $84.2 \%)$. However, this difference was not statistically significant $(P=0.053)$ (Figure 1). The incidence of grade 3 radiation dermatitis was comparable between the two groups $(P=0.894)$.

Predictive factors for grade 2 or worse radiation dermatitis were analyzed in evaluable patients. In univariate analysis, total RT dose was significantly associated with grade 2 or worse radiation dermatitis $(P=0.019)$ (Figure 2$)$. In multivariate analysis, total RT dose remained a significant predictive factor for grade 2 or worse radiation dermatitis (hazard ratio, 2.646; 95\% confidence interval, 1.123-6.231; $P=0.026$ ) (Table 4).

The mean maximal pain score was 3.76 (range, $0-7$; standard deviation, \pm 2.19 ) in the whole evaluable patient population. The mean maximal pain scores in the experimental and control groups were 2.53 (range, 0-6; standard deviation, \pm 1.62 ) and 3.95 (range, 1-7; standard deviation, \pm 2.07 ), respectively. The experimental group complained of less severe pain than the 
Table 2 Patient characteristics

\begin{tabular}{|c|c|c|c|}
\hline & $\begin{array}{l}\text { Experimental } \\
\text { group }(n=15)\end{array}$ & $\begin{array}{l}\text { Control } \\
\text { group }(n=19)\end{array}$ & $P$-value \\
\hline \multicolumn{4}{|l|}{ Age (years) } \\
\hline Median (range) & $\begin{array}{l}59.1 \\
(48.6-69.6)\end{array}$ & $\begin{array}{l}49.3 \\
(38.3-71.4)\end{array}$ & 0.018 \\
\hline \multicolumn{4}{|l|}{ Diabetes mellitus } \\
\hline Yes/no & $\begin{array}{l}3(20 \%) / \\
12(80 \%)\end{array}$ & $0 / 19(100 \%)$ & 0.041 \\
\hline \multicolumn{4}{|l|}{ Smoking } \\
\hline Current smoker & I (6.7\%) & 0 & 0.564 \\
\hline Former smoker & $\mathrm{I}(6.7 \%)$ & $2(10.5 \%)$ & \\
\hline Never smoker & $13(86.7 \%)$ & 17 (89.5\%) & \\
\hline \multicolumn{4}{|l|}{$\begin{array}{l}\text { ECOG performance } \\
\text { status }\end{array}$} \\
\hline \multirow[t]{2}{*}{$0 / 1$} & $8(53.3 \%) /$ & I3 (68.4\%)/ & 0.734 \\
\hline & 7 (46.7\%) & $6(31.6 \%)$ & \\
\hline \multicolumn{4}{|l|}{ T stage } \\
\hline In situ & $4(26.6 \%)$ & $5(26.3 \%)$ & 0.254 \\
\hline 1 & $10(66.7 \%)$ & $10(52.6 \%)$ & \\
\hline 2 & I (6.7\%) & $4(21.1 \%)$ & \\
\hline \multicolumn{4}{|l|}{$N$ stage } \\
\hline 0 & $12(80 \%)$ & 14 (73.7\%) & 0.312 \\
\hline I & $3(20 \%)$ & $3(15.7 \%)$ & \\
\hline 2 & 0 & $2(10.6 \%)$ & \\
\hline \multicolumn{4}{|l|}{ Molecular subtypes } \\
\hline Luminal & $10(66.7 \%)$ & 15 (78.9\%) & 0.478 \\
\hline Triple negative & $3(20 \%)$ & $2(10.6 \%)$ & \\
\hline HER2-positive & $2(13.3 \%)$ & $2(10.6 \%)$ & \\
\hline \multicolumn{4}{|c|}{ Body mass index $\left(\mathrm{kg} / \mathrm{m}^{2}\right)$} \\
\hline Median (range) & $\begin{array}{l}23.0 \\
(18.4-29.3)\end{array}$ & $\begin{array}{l}23.0 \\
(17.2-26.1)\end{array}$ & 0.270 \\
\hline \multicolumn{4}{|l|}{ Breast size $^{a}(\mathrm{cc})$} \\
\hline Median (range) & $\begin{array}{l}573.1 \\
(182.2-1,055.1)\end{array}$ & $\begin{array}{l}423.4 \\
(203.2-808.5)\end{array}$ & 0.015 \\
\hline \multicolumn{4}{|l|}{ Total RT dose (Gy) } \\
\hline Median (range) & $56(46-62)$ & $60(46-66)$ & 0.353 \\
\hline \multicolumn{4}{|c|}{ Lymph node irradiation } \\
\hline Yes/no & $\begin{array}{l}3(20 \%) / \\
12(80 \%)\end{array}$ & $\begin{array}{l}5(26.3 \%) / \\
14(73.7 \%)\end{array}$ & 0.764 \\
\hline \multicolumn{4}{|c|}{ Adjuvant chemotherapy } \\
\hline Yes/no & $\begin{array}{l}7(46.7 \%) / \\
8(53.3 \%)\end{array}$ & $\begin{array}{l}9(47.4 \%) / \\
10(52.6 \%)\end{array}$ & 0.821 \\
\hline
\end{tabular}

Note: ${ }^{2}$ Calculated from the clinical target volume of the whole breast in radiotherapy planning computer.

Abbreviations: ECOG, Eastern Cooperative Oncology Group; HER2, human epidermal growth factor receptor-2; RT, radiotherapy.

control group during RT. However, this difference was not statistically significant $(P=0.077)$.

The serum levels of EGF, TGF- $\beta$, and FGF in both groups are summarized in Table 5. There were no significant differences in serum level of growth factors between the two groups.

\section{Discussion}

In laughter therapy, it is not simply the exposure to a humorous stimulus, but the actual laughter that has
Table 3 Maximum grade of radiation dermatitis in experimental and control groups

\begin{tabular}{lll}
\hline $\begin{array}{l}\text { RTOG } \\
\text { grade }\end{array}$ & $\begin{array}{l}\text { Experimental } \\
\text { group }(\mathbf{n = 1 5})\end{array}$ & $\begin{array}{l}\text { Control } \\
\text { group }(\mathbf{n}=\mathbf{1 9})\end{array}$ \\
\hline 3 & $5(33.3 \%)$ & $7(36.8 \%)$ \\
2 & $5(33.3 \%)$ & $9(47.4 \%)$ \\
1 & $5(33.3 \%)$ & $2(10.5 \%)$ \\
0 & 0 & $1(5.3 \%)$ \\
\hline Abbreviation: RTOG, Radiation Therapy Oncology Group.
\end{tabular}

therapeutic efficacy. In patients who are exposed to a humorous stimulus in laughter therapy but do not laugh, a negative therapeutic response may even be triggered. Therefore, it is important to distinguish a humorous stimulus from laughter to determine the true therapeutic effect of laughter in laughter therapy research. ${ }^{18}$ In addition, because laughter is a subjective enjoyable feeling, it is very difficult to measure the amount of laughter and, to date, there has been no standard for measurement of the amount of laughter. Therefore, research on laughter therapy has unavoidable inherent flaws. In our study, to confirm that patients really laughed during therapy, the staff participated in laughter therapy and closely observed patients. Because all patients in our study mirthfully laughed more than ten times during each laughter therapy session, we could assess the true efficacy of laughter therapy. In addition, to control the amount of laughter, we organized the laughter therapy program to mainly trigger self-induced stimulated laughter. Because the brain is not able to distinguish spontaneous laughter (triggered by external stimuli from positive emotions) from

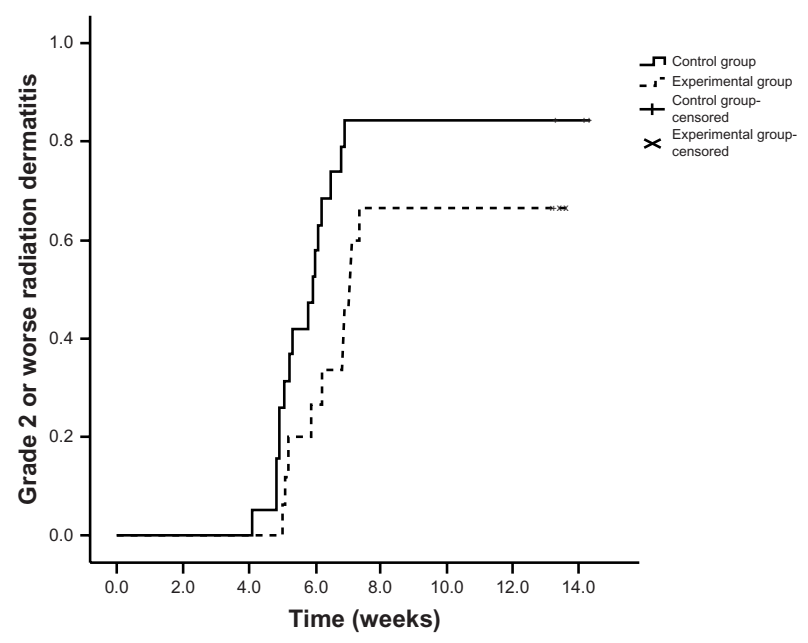

Figure I Incidence of grade 2 or worse radiation dermatitis in patient groups who received laughter therapy or not.

Notes: Patients who received laughter therapy during radiotherapy (experimental group) had a lower incidence of grade 2 or worse radiation dermatitis than patients who did not receive laughter therapy (control group). However, this difference was not statistically significant $(P=0.053)$. 


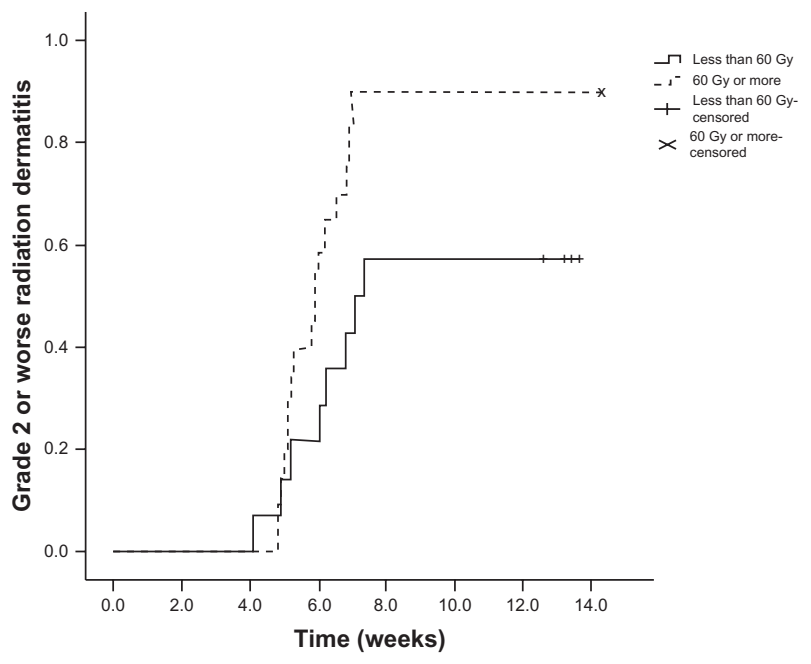

Figure $\mathbf{2}$ Incidence of grade 2 or worse radiation dermatitis according to total radiation dose.

Notes: The patients who received a total radiation dose of $\geq 60$ Gy had a higher incidence of grade 2 or worse radiation dermatitis than the patients who received $<60$ Gy $(P=0.019)$. In multivariate analysis, a statistically significant difference between the two groups remained (hazard ratio, 2.646; 95\% confidence interval, I.123-6.231; $P=0.026)$.

self-induced stimulated laughter (triggered by oneself at will), the therapeutic efficacy of these laughter types do not vary. ${ }^{26}$ Therefore, the therapeutic efficacy of laughter can be analyzed from self-induced stimulated laughter. Through our staff and a laughter therapy program that triggered mainly self-induced stimulated laughter, we sought to eliminate the inherent flaws of laughter therapy research, so that we could effectively control laughter and analyze the efficacy of laughter therapy.
There have been a few studies reporting that laughter has a beneficial role in the treatment of patients with skin problems. Kimata reported that allergen-induced wheal reactions were significantly reduced after induction of laughter in 26 patients with atopic dermatitis. ${ }^{23}$ Kimata also reported that laughter increased levels of breast-milk melatonin in mothers and allergic responses were reduced in infants who fed with their increased melatonin-containing milk. ${ }^{25}$ In this study, we assessed the efficacy of laughter in preventing or minimizing radiation dermatitis in patients with breast cancer. Patients who received laughter therapy exhibited a lower incidence of grade 2 or worse radiation dermatitis than patients who did not receive laughter therapy $(66.7 \%$ versus $84.2 \%)$. However, because of the small sample size, this difference was not statistically significant $(P=0.053)$. On the other hand, several studies have reported that laughter therapy increases pain tolerance, and consequentially alleviates pain. ${ }^{27-30}$ In this study, we also evaluated the effect of laughter therapy on pain in breast cancer patients who underwent RT. Patients who received laughter therapy reported less severe pain than patients who did not receive laughter therapy (maximum pain score; 2.53 versus 3.95). However, this difference was also not statistically significant $(P=0.077)$.

However, it is necessary to give attention to uneven patient characteristics between the two groups in this study. More patients in the experimental group had underlying diabetes mellitus and had larger breasts than patients in the control group. Diabetes mellitus and larger breasts are

Table 4 Analysis of predictive factors for grade 2 or worse radiation dermatitis

\begin{tabular}{|c|c|c|c|}
\hline \multirow[t]{2}{*}{ Variables } & \multirow{2}{*}{$\begin{array}{l}\text { Crude incidence rate } \\
\text { of grade } 2 \text { or worse } \\
\text { radiation dermatitis (\%) }\end{array}$} & \multicolumn{2}{|l|}{$P$-value } \\
\hline & & $\begin{array}{l}\text { Univariate } \\
\text { analysis }\end{array}$ & $\begin{array}{l}\text { Multivariate } \\
\text { analysis }\end{array}$ \\
\hline \multicolumn{4}{|l|}{ Age (years) } \\
\hline$<55$ versus $\geq 55$ & 87.5 versus 66.7 & 0.054 & 0.278 \\
\hline \multicolumn{4}{|l|}{ Total RT dose (Gy) } \\
\hline$<60$ versus $\geq 60$ & 57.1 versus 90.0 & 0.019 & 0.026 \\
\hline \multicolumn{4}{|l|}{ Lymph node irradiation } \\
\hline Yes versus no & 100 versus 69.2 & 0.065 & 0.159 \\
\hline \multicolumn{4}{|l|}{ Body mass index $\left(\mathrm{kg} / \mathrm{m}^{2}\right)$} \\
\hline$<23$ versus $\geq 23$ & 68.8 versus 83.3 & 0.423 & 0.585 \\
\hline \multicolumn{4}{|l|}{ Adjuvant chemotherapy } \\
\hline Yes versus no & 82.4 versus 70.6 & 0.420 & 0.541 \\
\hline \multicolumn{4}{|l|}{ Breast size ${ }^{a}(\mathrm{cc})$} \\
\hline$<450$ versus $\geq 450$ & 72.2 versus 81.3 & 0.430 & 0.349 \\
\hline \multicolumn{4}{|l|}{ Molecular subtypes } \\
\hline Luminal versus TN or HER2-positive & 80.0 versus 66.7 & 0.426 & 0.802 \\
\hline \multicolumn{4}{|l|}{ Laughter therapy } \\
\hline Yes versus no & 66.7 versus 84.2 & 0.053 & 0.178 \\
\hline
\end{tabular}

Note: a Calculated from the clinical target volume of the whole breast in radiotherapy planning computer. Abbreviations: HER2, human epidermal growth factor receptor-2; RT, radiotherapy; TN, triple negative. 
Table 5 Serum level of growth factors in experimental and control groups

\begin{tabular}{|c|c|c|c|}
\hline \multirow[t]{2}{*}{ Variables } & \multicolumn{2}{|c|}{ Mean \pm standard deviation } & \multirow[t]{2}{*}{$P$-value ${ }^{a}$} \\
\hline & Pre-RT & Post-RT & \\
\hline \multicolumn{4}{|l|}{ EGF (pg/mL) } \\
\hline Experimental group & $66.64 \pm 56.73$ & $66.02 \pm 55.55$ & 0.971 \\
\hline Control group & $100.74 \pm 78.57$ & $64.67 \pm 71.1$ & 0.180 \\
\hline$P$-value ${ }^{b}$ & 0.167 & 0.952 & \\
\hline \multicolumn{4}{|l|}{ TGF- $\beta$ (ng/mL) } \\
\hline Experimental group & $0.38 \pm 0.13$ & $0.36 \pm 0.11$ & 0.232 \\
\hline Control group & $0.4 I \pm 0.18$ & $0.35 \pm 0.13$ & 0.095 \\
\hline$P$-value ${ }^{\mathrm{b}}$ & 0.227 & 0.686 & \\
\hline \multicolumn{4}{|l|}{$\mathrm{FGF}(\mathrm{pg} / \mathrm{mL})$} \\
\hline Experimental group & $215.55 \pm 27.22$ & $223.97 \pm 38.97$ & 0.375 \\
\hline Control group & $232.02 \pm 67.11$ & $224.04 \pm 42.35$ & 0.128 \\
\hline$P$-value ${ }^{b}$ & 0.141 & 0.996 & \\
\hline
\end{tabular}

Notes: aPaired $t$-test; ' Independent $t$-test.

Abbreviations: EGF, epidermal growth factor; FGF, fibroblast growth factor; $\mathrm{RT}$, radiotherapy; TGF, transforming growth factor.

well-known risk factors for radiation-induced dermatitis in breast cancer patients treated with RT. ${ }^{9,31,32}$ Therefore, even though the patients who received laughter therapy had unfavorable characteristics that could increase the risk of radiation dermatitis, those patients showed a lower incidence of radiation dermatitis than patients who did not receive laughter therapy. We believe that these findings strengthen the favorable results of our study.

Although laughter therapy showed favorable therapeutic efficacy in preventing radiation dermatitis and alleviating pain in patients with breast cancer in our study, we could not draw definite conclusions because of the lack of statistical significance. Therefore, to confirm the favorable results of our study, additional studies with larger sample sizes are necessary. In addition, the mechanism of reduction of radiation dermatitis after laughter therapy has not yet been investigated. Kimata argued that TGF- $\beta$ had some role in minimizing the process of allergic responses in patients with atopic dermatitis who received laughter therapy. ${ }^{25}$ In this study, we checked the serum levels of EGF, TGF- $\beta$, and FGF at the initiation of RT and 1 week after RT completion of all patients to find potentially important factors in minimizing radiation dermatitis through laughter therapy. However, we could not find any significant factors. Therefore, to disclose the exact mechanism of reduction of radiation dermatitis after laughter therapy, further studies are necessary. However, laughter therapy does not require large amounts of time or money and the side effects of laughter therapy are very limited, so we suggest that laughter therapy can be implemented easily and cost-effectively as complementary therapy in patients with breast cancer without confirmation of our favorable results. We hope more physicians are willing to introduce laughter therapy as a complement to conventional treatments such as surgery, RT, and chemotherapy for patients with breast cancer.

There were some limitations in this study. First, this is a pilot study with small sample size. Therefore, this study lacks sufficient data to draw definite conclusions. Second, because the patients were not blinded to their assignment, their evaluation of pain score might be over- or underestimated. However, the radiation oncologist who scored the grade of radiation dermatitis was blinded. Third, because this is not a randomized study, there were different baseline characteristics between groups. Fourth, we could not control the possibility of confounding laughter in the control group. These limitations make it difficult to interpret the results of this study. However, since this is the first study to assess the therapeutic efficacy of laughter therapy for preventing radiation dermatitis in patients with breast cancer, we believe that this study provides some interesting and positive evidence that will encourage further research. If a prospective randomized trial with large sample sizes is conducted, we can draw more reliable conclusions regarding the efficacy of laughter therapy.

\section{Conclusion}

This single-blind prospective pilot study showed that laughter therapy can have a beneficial role in preventing radiation dermatitis in patients with breast cancer. To confirm the results of our study, well-designed randomized studies with large sample sizes are required.

\section{Acknowledgments}

The authors would like to thank Jeom Ok Kim, Instructor, Korea Laughter Research Institute, for her support in the implementation of laughter therapy and Kwang Sik Suh, PhD, Kyung Hee University Medical Center, for his assistance in data analysis.

This research was supported by the Kyung Hee University Research Fund in 2013 (KHU-20130844).

All authors have made substantive contributions to the article and assume full responsibility for its content. Also, all authors fulfilled the International Committee of Medical Journal Editors requirements for authorship.

\section{Disclosure}

This research was supported by the Kyung Hee University Research Fund in 2013 (KHU-20130844). The authors report no conflicts of interest in this work. 


\section{References}

1. Ha B, Suh HS, Lee J, Lee KJ, Lee R, Moon BI. Long-term results of forward intensity-modulated radiation therapy for patients with earlystage breast cancer. Radiat Oncol J. 2013;31(4):191-198.

2. Harper JL, Franklin LE, Jenrette JM, Aguero EG. Skin toxicity during breast irradiation: pathophysiology and management. South Med J. 2004;97(10):989-993.

3. Graham PH, Plant N, Graham JL, et al. A paired, double-blind, randomized comparison of a moisturizing durable barrier cream to $10 \%$ glycerine cream in the prophylactic management of postmastectomy irradiation skin care: trans Tasman Radiation Oncology Group (TROG) 04.01. Int J Radiat Oncol Biol Phys. 2013;86(1):45-50.

4. Kong M, Hong SE. Topical use of recombinant human epidermal growth factor (EGF)-based cream to prevent radiation dermatitis in breast cancer patients: a single-blind randomized preliminary study. Asian Pac J Cancer Prev. 2013;14(8):4859-4864.

5. Pinnix C, Perkins GH, Strom EA, et al. Topical hyaluronic acid vs standard of care for the prevention of radiation dermatitis after adjuvant radiotherapy for breast cancer: single-blind randomized phase III clinical trial. Int J Radiat Oncol Biol Phys. 2012;83(4):1089-1094.

6. Hemati S, Asnaashari O, Sarvizadeh M, et al. Topical silver sulfadiazine for the prevention of acute dermatitis during irradiation for breast cancer. Support Care Cancer. 2012;20(8):1613-1618.

7. Kirova YM, Fromantin I, De Rycke Y, et al. Can we decrease the skin reaction in breast cancer patients using hyaluronic acid during radiation therapy? Results of phase III randomised trial. Radiother Oncol. 2011;100(2):205-209.

8. Merchant TE, Bosley C, Smith J, et al. A phase III trial comparing an anionic phospholipid-based cream and aloe vera-based gel in the prevention of radiation dermatitis in pediatric patients. Radiat Oncol. 2007;2:45

9. Pommier P, Gomez F, Sunyach MP, D’Hombres A, Carrie C, Montbarbon X. Phase III randomized trial of Calendula officinalis compared with trolamine for the prevention of acute dermatitis during irradiation for breast cancer. J Clin Oncol. 2004;22(8):1447-1453.

10. Cousins N. Anatomy of an illness (as perceived by the patient). NEngl J Med. 1976;295(26):1458-1463.

11. Bellert JL. Humor. A therapeutic approach in oncology nursing. Cancer Nurs. 1989;12(2):65-70.

12. Erdman L. Laughter therapy for patients with cancer. Oncol Nurs Forum. 1991;18(8):1359-1363.

13. Penson RT, Partridge RA, Rudd P, et al. Laughter: the best medicine? Oncologist. 2005;10(8):651-660.

14. Saper B. The therapeutic use of humor for psychiatric disturbances of adolescents and adults. Psychiatr Q. 1990;61(4):261-272.

15. Gelkopf M, Kreitler S, Sigal M. Laughter in a psychiatric ward. Somatic, emotional, social, and clinical influences on schizophrenic patients. J Nerv Ment Dis. 1993;181(5):283-289.
16. van Alphen PJ. [Humor as diagnostic and therapeutic tool in psychiatry. Laughter is healthy]. TVZ. 1997;107(22):674-677. Dutch.

17. Basmajian JV. The elixir of laughter in rehabilitation. Arch Phys Med Rehabil. 1998;79(12):1597.

18. Bennett MP, Zeller JM, Rosenberg L, McCann J. The effect of mirthful laughter on stress and natural killer cell activity. Altern Ther Health Med. 2003;9(2):38-45.

19. Bukutu C, Le C, Vohra S. Asthma: a review of complementary and alternative therapies. Pediatr Rev. 2008;29(8):e44-e49.

20. Borod M. SMILES - toward a better laughter life: a model for introducing humor in the palliative care setting. $J$ Cancer Educ. 2006;21(1):30-34.

21. Bennett M, Lengacher C. Use of complementary therapies in a rural cancer population. Oncol Nurs Forum. 1999;26(8):1287-1294.

22. Lengacher CA, Bennett MP, Kip KE, et al. Frequency of use of complementary and alternative medicine in women with breast cancer. Oncol Nurs Forum. 2002;29(10):1445-1452.

23. Kimata $H$. Effect of humor on allergen-induced wheal reactions. JAMA. 2001;285(6):738.

24. Kimata H. Laughter counteracts enhancement of plasma neurotrophin levels and allergic skin wheal responses by mobile phone-mediated stress. Behav Med. 2004;29(4):149-152.

25. Kimata H. Laughter elevates the levels of breast-milk melatonin. J Psychosom Res. 2007;62(6):699-702.

26. Mora-Ripoll R. The therapeutic value of laughter in medicine. Altern Ther Health Med. 2010;16(6):56-64.

27. Yoshino S, Fujimori J, Kohda M. Effects of mirthful laughter on neuroendocrine and immune systems in patients with rheumatoid arthritis. J Rheumatol. 1996;23(4):793-794.

28. Weisenberg M, Raz T, Hener T. The influence of film-induced mood on pain perception. Pain. 1998;76(3):365-375.

29. Cogan R, Cogan D, Waltz W, McCue M. Effects of laughter and relaxation on discomfort thresholds. J Behav Med. 1987;10(2):139-144.

30. Van Zandt S, LaFont C. Can a laugh a day keep the doctor away? J Pract Nurs. 1985;35(3):32-35.

31. Fernando IN, Ford HT, Powles TJ, et al. Factors affecting acute skin toxicity in patients having breast irradiation after conservative surgery: a prospective study of treatment practice at the Royal Marsden Hospital. Clin Oncol (R Coll Radiol). 1996;8(4):226-233.

32. Fisher J, Scott C, Stevens R, et al. Randomized phase III study comparing Best Supportive Care to Biafine as a prophylactic agent for radiation-induced skin toxicity for women undergoing breast irradiation: Radiation Therapy Oncology Group (RTOG) 97-13. Int J Radiat Oncol Biol Phys. 2000;48(5):1307-1310.
OncoTargets and Therapy

\section{Publish your work in this journal}

OncoTargets and Therapy is an international, peer-reviewed, open access journal focusing on the pathological basis of all cancers, potential targets for therapy and treatment protocols employed to improve the management of cancer patients. The journal also focuses on the impact of management programs and new therapeutic agents and protocols on
Dovepress

patient perspectives such as quality of life, adherence and satisfaction. The manuscript management system is completely online and includes a very quick and fair peer-review system, which is all easy to use. Visit http://www.dovepress.com/testimonials.php to read real quotes from published authors. 